\title{
An Investigation of the Effects of Exercises Applied on Unstable Surfaces on High School Students
}

\author{
Ali Ozuak ${ }^{1}$, Kamil Erdem ${ }^{1}$ \\ ${ }^{1}$ Marmara University, Faculty of Sport Sciences, Istanbul, Turkey \\ Correspondence: Ali Ozuak, Marmara University, Faculty of Sport Sciences, Istanbul, Turkey
}

Received: March 13, 2019

Accepted: May 5, 2019 Online Published: May 10, 2019

doi:10.11114/jets.v7i6.4140

URL: https://doi.org/10.11114/jets.v7i6.4140

\begin{abstract}
In this study, it was aimed to determine the effects of plyometric exercises applied on unstable platforms on static and dynamic balances of soccer players who continued their high school education. In the study, male soccer players with similar socio-economic status between the ages of 14 and 16 formed the study group (SG; $\mathrm{n}=24$; age $=15.08 \pm 1.36$ ) and the control group $(\mathrm{CG} ; \mathrm{n}=22$; age $=15.22 \pm 1.62)$. Static Balance Eyes Open (SB-EO), Static Balance Eyes Closed (SB-EC) and Dynamic Balance tests (DB) were applied on the SG and CG as pre- and post-tests for both dominant leg (DL) and non-dominant leg (NDL). SG athletes were subjected to plyometric exercises on unstable surfaces for sixteen sessions that were integrated into the physical education lessons in high school while CG athletes performed only a traditional soccer training program. As a result of the statistical analyses, when the pre-post test scores of the SG were examined, dynamic balance-dominant leg (DB-DL; $\mathrm{p}=0.03$ ), dynamic balance-non-dominant leg (DB-NDL; $\mathrm{p}=0.03$ ), static balance eyes open-dominant leg (SB-EO-DL; $\mathrm{p}=0$ 01), static balance eyes closed -dominant leg (SB-EC-DL; $\mathrm{p}=0.03$ ) and static balance eyes closed-non-dominant leg (SB-EC-NDL; $\mathrm{p}=0.01$ ) measurements were found statistically significant $(\mathrm{p}<0.05)$ while the CG had statistical improvements only in SB-EO-DL measurements $(\mathrm{p}=0.03)$. When the differences between the two groups were examined, only SB-EC-DL measurements were found statistically significant in favor of the $\mathrm{SG}(\mathrm{p}=0.03)$. In conclusion, especially the improvement of DL observed in the SG is important for optimum performance considering that it is necessary to use both legs effectively in soccer. Considering the multitude of activities performed on a single leg in soccer, it is thought that the increase in bilateral balance can improve the skills that determine soccer performance in difficult conditions such as dribbling, shooting and passing.
\end{abstract}

Keywords: static balance, dynamic balance, soccer, physical education

\section{Introduction}

Soccer is the most popular game in the world, with millions of participants and fans. It is the primary sport of Asia, Europe, Africa and South America. It is the most researched team sport because of its popularity and financial interest (Atan, 2009). Nowadays, soccer requires a high degree of effort in which the participants experience various actions with characteristics such as strength, speed, agility, balance, stability, flexibility and sufficient endurance altogether (Bloomfield et al., 2007; Helgerud et al., 2001). In soccer, technique, tactics and physical fitness are the three important factors that determine performance. All of these can have roles at different ratios depending on the characteristics of the match (Bangsbo, 1996; Özmen, 1999; Reilly et al., 2000).

Along with technical abilities, soccer is a sport that requires static, half-dynamic and dynamic balance (Dunsky et al., 2017). Balance is the state in which all the forces operating on the body are balanced in such a manner that the center of mass is within the stability limits, which are the margins of the base of support (Sharma and Multani, 2017). Body balance can be dynamic or static by containing the center of mass in the base of support which is defined by the feet. In static balance, the center of mass is fixed during movement. In this situation, the sense of balance protects the center of gravity within the base of support which is defined by the feet.

On the other hand, with dynamic balance, both the center of mass and base of support are in constant movement and the center of gravity never aligns itself to the base of support during the stopping phase of the movement (Melo et al., 2017). Dynamic balance has vital importance for many sports and daily life activities, and has become an important aspect for displaying skill in complex movements and improving sport performance, and as a result has become an important subject for evaluating stability (Ringhof and Stein, 2018; Çelenk et al., 2018). 
Soccer requires static balance and dynamic balance features like many other technical abilities. A lot of abilities such as passing, kick-ups, dribbling, or controlling the ball are performed while standing on one leg. Balance plays a pivotal role in situations such as facing players, impacts, slippery grass, changes in the ball's direction and during a tough situation while moving (Evangelos, 2012) and can be considered as an indicator of performance in soccer (Paillard et al., 2006).

Soccer players, by targeting both legs in balance training programs, can work out invaluable solutions in the game and can perform technical abilities with their non-dominant legs while their dominant legs take over the balance task (Evangelos, 2012). Especially in sports branches with sudden movements (Alpay and Işık, 2017), keeping the whole body in balance and being in balance while performing rapid position changes to carry out the necessary movements for that sport is crucial (Atılgan, 2013).

The aim of this study was to determine the changes in static and dynamic balance of dominant and non-dominant legs of young soccer players who were subjected to plyometric exercises on unstable surfaces. As the hypothesis of the study, it is thought that the athletes who did additional plyometric exercises on unstable grounds during physical education lessons would show better improvements in the balance of both legs when compared with athletes who did traditional soccer training only.

\section{Method}

\subsection{Work Group}

In the study, 46 male amateur soccer players who continued their high school education formed the study group (SG; $\mathrm{n}=24$; age $=15.42 \pm 1.36$ years) and the control group (CG; $\mathrm{n}=22$; age $=15.66 \pm 1.62$ years) from two different clubs with similar socio-economic status in Turkey. Sampling was conducted according to the societies. This age group is thought to be the ideal age for balance enhancement as a reason to choose soccer players (Myer et al., 2004). All young players who participated in the study have soccer licenses, so they had already passed the medical examination by the Turkish Soccer Federation in pre-season. The parents of the volunteers who participated in the study were informed about the study and the parents' signed permission documents were obtained. In addition, the two soccer clubs and the two different high schools that the SG athletes continue their educations participating in the study were informed about the training program to be implemented and the clubs' and high schools' signed permission documents were obtained as well. No fees were paid or received for the participants. The forty-six athletes forming the SG and the CG were subjected to SB and DB tests as pre- and post-tests. SG athletes were given three sets of training programs of training load for 30 seconds and rest period for 1 minute on unstable surfaces such as bosu ball and trampoline which were integrated into the physical education lessons for 8 weeks. Rest periods between sets were given as 5 minutes (Table 5). The SG players continued their traditional soccer trainings in their own clubs, while the CG athletes practiced only traditional soccer trainings.

\subsection{Data Collection Tool and Processing Method}

Dynamic Balance Test: The Y Balance test, which was modified from the Star Excursion Balance Test, was used to measure DB of the young soccer players (Plisky et al., 2006). The test was done without shoes. First, the test trials were done for all three directions. The subject stood on one foot on the center of the plate without crossing the red line and tried to reach towards anterior, posteromedial and posterolateral directions with the free foot. Two reach tests were done on all directions for both legs. The subjects, having their toes behind the red line, stood on the platform and pushed the indicator on the target area. Maximal reach distance was measured by reading the strip measure on the reach indicator. The best result for every direction was used for analysis. The sum of the maximal data gathered from the three directions was divided by limb length times three and then was multiplied by one hundred to determine the composite reach distance (composite reach distance $(\%)=$ Sum of the 3 reach directions / 3 times the limb length * 100 equation (Shaffer et al., 2013). The subject's right leg length was measured from the lowermost anterosuperior iliac to the medial malleolus' farthest section (Plisky et al., 2006). Measurement was repeated under the following circumstances: if the other foot touched the floor or the subject fell out of the platform, if the subject kicked the reach indicator, if the subject put their foot on the indicator and used it to support his stance, or if the subject could not return the reach foot back to the starting point (Plisky et al., 2006).

Static Balance Test: SB measurements of the young soccer players were conducted in the laboratory during the relaxed position of the body and the necessary precautions were taken to avoid any effect arising from environmental factors (noise, temperature). The measurements were performed by using a Force Platform. Verbal and visual information about the tests was given to the subjects. Before the balance tests (for all measurements), the stabilometer was calibrated and the subjects could settle on the balance platform with their feet naked. Measurements were performed first with the EO and then with the EC for the DL and NDL, and the areas of oscillation were determined. In the measurements where the smallest oscillation field pointed to the best balance, two trials were made for each measurement and the best ratings 
were taken. Data were recorded in forms and statistically interpreted (Yaggie and Campbell, 2006).

\subsection{Statistical Analysis}

The data obtained in the study were analyzed using the SPSS (Statistical Package for Social Sciences) for Windows 21.0 program. The Shapiro-Wilks test was used to identify the distributions of the variables, and the distributions were found to be normal. Descriptive statistical methods (number, percentage, mean, standard deviation) were used in the evaluation of the data. In the statistical analysis, the data obtained were assessed by Wilcoxon analysis of nonparametric tests to compare pre- and post-test values within the groups themselves, and the Mann-Whitney U test was used for the comparison of parameters between the two groups. The findings were evaluated at $95 \%$ confidence interval and $5 \%$ significance level.

\section{Results}

Table 1. Descriptive characteristics of participants

\begin{tabular}{llcccc}
\hline Parameters & \multicolumn{1}{c}{ Groups } & Min. & Max. & Avg. & Std. Dev. \\
\hline \multirow{2}{*}{ Weight $(\mathrm{kg})$} & Study $(\mathrm{n}=24)$ & 31.60 & 58.10 & 42.75 & 8.32 \\
& Control $(\mathrm{n}=22)$ & 30.80 & 55.70 & 42.05 & 8.02 \\
\cline { 2 - 6 } Height $(\mathrm{m})$ & Study $(\mathrm{n}=24)$ & 1.41 & 1.59 & 1.50 & 0.06 \\
& Control $(\mathrm{n}=22)$ & 1.37 & 1.67 & 1.51 & 0.10 \\
\cline { 2 - 6 } BMI $\left(\mathrm{kg} / \mathrm{m}^{2}\right)$ & Study $(\mathrm{n}=24)$ & 15.24 & 26.17 & 18.81 & 2.90 \\
& Control $(\mathrm{n}=22)$ & 15.13 & 22.26 & 18.23 & 2.06 \\
\hline
\end{tabular}

BMI: Body Mass Index; Min.=Minimum; Max.=Maximum; Avg.=Average; Std. Dev.=Standard Deviation

Table 2. Analysis of pre-post test scores of Dynamic Balance tests

\begin{tabular}{|c|c|c|c|c|c|c|c|}
\hline Parameters & Group & Test & Min. & Max. & Avg. & Std. Dev. & $\mathrm{p}$ \\
\hline \multirow{4}{*}{ DB-DL } & \multirow{2}{*}{$\mathrm{CG}(\mathrm{n}=22)$} & Pre-test & 70.42 & 84.17 & 77.44 & 3.92 & \multirow[b]{2}{*}{0.16} \\
\hline & & Post-test & 71.97 & 88.81 & 78.83 & 4.77 & \\
\hline & \multirow{2}{*}{ SG $(n=24)$} & Pre-test & 69.35 & 93.81 & 77.73 & 6.31 & \multirow{2}{*}{$0.03 *$} \\
\hline & & Post-test & 69.65 & 94.65 & 83.54 & 6.13 & \\
\hline \multirow{4}{*}{ DB-NDL } & $C G(n-22)$ & Pre-test & 69.83 & 81.13 & 76.23 & 3.05 & \multirow{2}{*}{0.10} \\
\hline & $c u(n=22)$ & Post-test & 71.33 & 84.92 & 78.61 & 3.70 & \\
\hline & \multirow{2}{*}{$S G(n=24)$} & Pre-test & 68.97 & 92.68 & 77.35 & 6.46 & \multirow{2}{*}{$0.03 *$} \\
\hline & & Post-test & 69.51 & 94.23 & 82.45 & 6.76 & \\
\hline
\end{tabular}

$\mathrm{CG}=$ Control Group; SG=Study Group; DB=Dynamic Balance; DL=Dominant Leg; NDL=Non-dominant Leg; T=Test; Min.=Minimum; Max.=Maximum; Avg.=Average; Std. Dev.=Standard Deviation; $\mathrm{P}=$ Significance $\left(\mathrm{p}<0.05^{*}\right)$

As a result of the DB test, statistically significant improvement was observed in both DL $(p=0.03)$ and NDL ( $p=0.03)$ in the $S G$ athletes, while no statistically significant change was observed in the CG athletes ( $p>0.05)$.

Table 3. Analysis of pre-post test scores of Static Balance tests

\begin{tabular}{|c|c|c|c|c|c|c|c|}
\hline Parameters & Group & Test & Min. & Max. & Avg. & Std. Dev. & $\mathrm{p}$ \\
\hline \multirow{4}{*}{ SB-EO-DL } & \multirow{2}{*}{$\mathrm{CG}(\mathrm{n}=22)$} & Pre-test & 2.15 & 5.80 & 4.05 & 1.03 & \multirow{2}{*}{$0.03^{*}$} \\
\hline & & Post-test & 1.98 & 5.39 & 3.54 & 0.88 & \\
\hline & \multirow{2}{*}{$\mathrm{SG}(\mathrm{n}=24)$} & Pre-test & 2.08 & 7.82 & 4.59 & 1.52 & \multirow{2}{*}{$0.01 *$} \\
\hline & & Post-test & 1.96 & 7.49 & 3.55 & 1.34 & \\
\hline \multirow{4}{*}{ SB-EC-DL } & \multirow{2}{*}{$\mathrm{CG}(\mathrm{n}=22)$} & Pre-test & 6.72 & 14.51 & 10.80 & 2.73 & \\
\hline & & Post-test & 5.69 & 15.02 & 9.43 & 3.18 & \multirow{2}{*}{0.67} \\
\hline & \multirow{2}{*}{ SG (n=24) } & Pre-test & 6.01 & 14.72 & 10.45 & 2.63 & \\
\hline & & Post-test & 3.99 & 12.31 & 8.02 & 2.47 & $0.03 *$ \\
\hline \multirow{4}{*}{ SB-EO-NDL } & \multirow{2}{*}{$\mathrm{CG}(\mathrm{n}=22)$} & Pre-test & 1.79 & 6.94 & 4.05 & 1.38 & \multirow{2}{*}{0.78} \\
\hline & & Post-test & 2.76 & 5.43 & 4.03 & 0.69 & \\
\hline & \multirow{2}{*}{$\mathrm{SG}(\mathrm{n}=24)$} & Pre-test & 2.00 & 6.18 & 4.03 & 1.47 & \multirow{2}{*}{0.15} \\
\hline & & Post-test & 2.06 & 9.75 & 3.98 & 1.72 & \\
\hline \multirow{4}{*}{ SB-EC-NDL } & \multirow{2}{*}{$\mathrm{CG}(\mathrm{n}=22)$} & Pre-test & 5.54 & 15.36 & 10.82 & 2.65 & \multirow{2}{*}{0.22} \\
\hline & & Post-test & 4.83 & 14.41 & 9.84 & 2.70 & \\
\hline & \multirow{2}{*}{$\mathrm{SG}(\mathrm{n}=24)$} & Pre-test & 6.15 & 19.96 & 11.50 & 3.74 & \multirow{2}{*}{$0.01 *$} \\
\hline & & Post-test & 3.63 & 16.94 & 9.59 & 3.99 & \\
\hline
\end{tabular}

CG=Control Group; SG=Study Group; SB=Static Balance; DL=Dominant Leg; NDL=Non-dominant Leg; EO= Eyes open; EC=Eyes closed; T=Test; Min.=Minimum; Max.=Maximum; Avg.=Average; Std. Dev.=Standard Deviation; $\mathrm{P}=$ Significance $\left(\mathrm{p}<0.05^{*}\right)$ 
As a result of the statistical analysis of pre- and post- SB test; the SG players had statistically significant improvements in SB-EO-DL ( $\mathrm{p}=0.01)$, SB-EC-DL $(\mathrm{p}=0.034)$ and SB-EC-NDL $(\mathrm{p}=0.01)$ measurements while the CG players had statistically significant improvement only in SB-EO-DL measurement $(\mathrm{p}=0.03)$.

Table 4. Change in scores of groups in Dynamic Balance and Static Balance Parameters

\begin{tabular}{|c|c|c|c|c|c|c|}
\hline Parameters & Group & Min. & Max. & Avg. & Std. Dev. & $p$ \\
\hline \multirow{2}{*}{ DB-DL } & CG $(n=22)$ & -0.48 & 5.08 & 1.81 & 1,52 & \multirow{2}{*}{0.84} \\
\hline & $\mathrm{SG}(\mathrm{n}=24)$ & -0.63 & 7.63 & 2.38 & 1.92 & \\
\hline \multirow{2}{*}{ DB-NDL } & CG $(n=22)$ & 0.46 & 5.23 & 2.09 & 1.13 & \multirow{2}{*}{0.95} \\
\hline & $\mathrm{SG}(\mathrm{n}=24)$ & 0.01 & 6.00 & 2.38 & 1.83 & \\
\hline \multirow{2}{*}{ SB-EO-DL } & CG $(n=22)$ & -1.05 & 2.97 & 0.63 & 1.06 & \multirow{2}{*}{0.46} \\
\hline & $\mathrm{SG}(\mathrm{n}=24)$ & -0.73 & 2.09 & 0.51 & 0.75 & \\
\hline \multirow{2}{*}{ SB-EC-DL } & CG $(n=22)$ & -1.66 & 4.10 & 1.37 & 1.68 & \multirow{2}{*}{$0.03 *$} \\
\hline & $\mathrm{SG}(\mathrm{n}=24)$ & -2.90 & 6.95 & 2.42 & 2.82 & \\
\hline \multirow{2}{*}{ SB-EO-NDL } & CG $(n=22)$ & -3.57 & 1.99 & 0.09 & 1.16 & \multirow{2}{*}{0.38} \\
\hline & $\mathrm{SG}(\mathrm{n}=24)$ & -2.10 & 2.21 & 0.00 & 1.23 & \\
\hline \multirow{2}{*}{ SB-EC-NDL } & CG $(n=22)$ & -6.85 & 9.42 & 1.50 & 4.48 & \multirow{2}{*}{0.86} \\
\hline & $\mathrm{SG}(\mathrm{n}=24)$ & -3.33 & 4.41 & 1.18 & 1.81 & \\
\hline
\end{tabular}

CG=Control Group; SG=Study Group; DB=Dynamic Balance; SB=Static Balance; DL=Dominant Leg; NDL=Non-dominant Leg; EO=Eyes open; EC=Eyes closed; T=Test; Min.=Minimum; Max.=Maximum; Avg.=Average; Std. Dev. $=$ Standard Deviation; $\mathrm{P}=$ Significance $\left(\mathrm{p}<0.05^{*}\right)$

When the differences between the two groups were examined, SB-EC-DL measurements were found statistically significant in favor of the $\mathrm{SG}$ players $(\mathrm{p}=0.03)$.

\section{Discussion}

In-group changes: When the pre- and post-test scores of the $\mathrm{SG}$ were examined, for DB measurements in DL ( $\mathrm{p}=0.03$ ) and in NDL ( $\mathrm{p}=0.03$ ), for SB-EO measurements in DL ( $\mathrm{p}=0.01)$, for SB-EC measurements in DL ( $\mathrm{p}=0.03)$ and in NDL $(\mathrm{p}=0.01)$, measurements were found statistically significant $(\mathrm{p}<0.05)$. When the pre- and post-test scores of the CG players were examined, it was found that only the SB-EO scores increased in statistically significant terms $(\mathrm{p}=0.03)$.

Intergroup Differences: Only SB with EC measurements were found statistically significant in favor of the $\mathrm{SG}(\mathrm{p}=0.03$ ). The balance characteristic of an athlete is affected by the surface, its movements, or both. In this study, the results of the exercises performed on unstable surfaces for twelve weeks on DB and SB have been evaluated and it was seen that the SG athletes working on unstable platforms made more progress than the CG athletes in terms of all parameters. In soccer, the effect of balance during the game has different significance levels according to DL and NDL. While it is stated in the literature that soccer is the most ideal sport branch that improves balance (Jakobsen et al., 2010), it is reported in another study emphasizing the importance of balance in soccer that soccer players in the national league are better when SB and DB measurements of players are compared (Paillard et al., 2006).

In the present study, the SG athletes showed significant improvement both in DL and NDL values in DB measurements $(p<0.05)$. Although the CG athletes did not have a special training, they also observed an impact on their DB because of the nature of the soccer game. However, it was seen that they could obtain more effective results when supported with unstable ground trainings. While the leg that players use to kick the ball during play is the DL, the NDL is used as balance leg. The enhancement of the balance ability of the DL is particularly valuable because the NDL is also used to make a difference during complicated positions in soccer, in which case the DL is responsible for the balance.

However, the improvement of DB DL gains importance for the elimination of bilateral differences. The improvement of NDL can be regarded as normal since the CG player who performs classical soccer training often uses the NDL as a balance leg. In this respect, it is suggested that classical soccer practices should be supported by DB exercises applied on unstable grounds.

In the literature, in support of this study, Erdem and Akyüz (2017) found that DL sway parameters of SG athletes who were subjected to balance and core exercises were statistically significant compared to those of CG athletes ( $\mathrm{p}<0.05$ ). The results showed that training on unstable ground was more effective than traditional soccer training methods. They argued that the muscle and nervous systems, which tried to maintain balance in more difficult conditions, were effective in reducing the sway. In another study overlapping with our study, Filipa et al. (2010) applied neuromuscular training for female athletes $(n=10$; age $=15.4 \pm 1.5)$ and traditional soccer training for $C G$ players $(n=10$; age $=14.7 \pm 0.8)$. When they evaluated the right and left leg DB measurements with the Star Excursion Balance Test (SEBT) battery, they determined the combined normalized leg length values of the SEBT for both the CG and the SG that was given the neuromuscular training program. The results of their study showed that the development in both legs of the athletes in 
the SG who were given the neuromuscular training program was statistically significant $(\mathrm{p}<0,05)$.

It is seen that training made on unstable grounds is more effective on SB than other training methods due to the dynamic movements. It can be considered that the muscle and nervous systems, which try to maintain balance under more difficult conditions, have an effect on the reduction of oscillations in the stabilized positions. In addition, DB development of the SG athletes may have had a positive impact on SB. As seen in the present study, statistical improvement was found in the measurements of SB in the athletes, especially in the DL, both with EO and EC ( $<<0.05)$. However, SG athletes also showed statistical improvement in NDL measurement with closed eyes $(p<0.05)$. Unstable grounds restrict sensory and motor feedback cycles and cause increases in body oscillation, i.e. loss of balance and muscle activity. This requires a significant change in the capacity of incoming proprioceptive information, i.e. a high-level control system. If traditional soccer practices are supported by plyometric exercises that are carried out on unstable grounds and which are effective in the development of strength, they can help athletes to achieve the necessary skills more easily in complex situations where abilities such as coordination, agility and balance are very important.

Unstable ground materials such as bosu ball and trampoline that were used in the present study could also help to improve the performance of young soccer players as well as to prevent possible ligament injuries. In the literature, Tropp et al. (1984) found that the use of uniaxial and multi-axis balance discs significantly reduced postural oscillation values in soccer. In another study, Blackburn et al. (2000) divided their athletes into a CG, a force training group, a proprioceptive training group, and a force proprioceptive training group. The researchers found that there was no statistical difference between the groups in the outcome of the study but reported that the improvements in proprioception and muscular strength were equally effective in improving joint stability and stabilizing. However, these developments in SB are very valuable because the improved balance characteristic of younger ages can contribute to their becoming elite soccer players by making them more ergonomic by carrying younger soccer players' bio-motor features to the next years and making them able to perform technical skills specific to soccer. It is stated that starting neuromuscular training such as balance, agility and proprioception in this period will make a great contribution as an important advantage due to the peak height of males in the adolescence period (Malina et al., 2004) and the decrease in balance and coordination (Myer et al., 2004). These competences are important characteristics affecting performance in soccer (Little and Williams, 2005). In another study Zech et al. (2010) concluded that balance exercises are effective in postural and neuromuscular control enhancements.

In addition to the positive effects of the balance trainings mentioned above, the effects on motoric properties of plyometric exercises are known in the literature. In the present study, the effect of the combined training program on the parameters related to balance has been established $(\mathrm{p}<0.05)$, but the effect on motoric properties has not been investigated. In a study on this subject in the literature, Chaouachi et al. (2014) indicated that balance and plyometric combined training enhanced activities such as $10 \mathrm{~m}$ sprints and shuttle runs to a greater degree.

In conclusion, the development in the musculoskeletal system, which does not move equally with the neuromuscular development during the adolescence period, may lead to neuromuscular imbalances that may make the individual highly susceptible to injury. Since the rapid growth of long bones in the skeletal system during the adolescence period is not the desired development of muscle-nervous system control, the upward movement of the center of gravity can make it difficult for individuals to maintain their balance. For this reason, it is recommended that these programs should be started within sports programs at schools (McLeod et al., 2009). In the present study, the improvement observed in the SG is important for optimum performance considering that it is necessary to use both legs effectively in soccer. Considering the multitude of activities performed on one foot in soccer, it is thought that the increase in bilateral balance can improve the skills that determine soccer performance such as dribbling, shooting and passing in difficult conditions. Both in the present study and in the studies conducted in the literature, as well as the studies on unstable surfaces, there are positive effects on balance as well as on strength and agility development in the plyometric studies. At the same time, combined training could be an important consideration for reducing the high velocity impacts of plyometric training. This reduction in stretch-shortening cycle (SSC) stress on the neuromuscular system with the replacement of balance and landing exercises might help to alleviate the overtraining effects of excessive repetitive high load activities. In this respect, it is important to integrate combined training programs into training plans and to include them in the annual training plan. In subsequent studies it is suggested that similar training programs should be supplemented with tests that measure technical skills in soccer, with the effect on motoric properties. 
Table 5. Training Program

\begin{tabular}{l|l|l}
\hline Exercises & First 4 weeks & Last 4 weeks \\
\hline Running men knees on bosu ball & $30 \mathrm{sec}$. & \\
\hline Dynamic lunges on bosu ball & 30 sec. & \\
\hline Wide squat and jump on bosu ball & 30 sec. & \\
\hline Double-leg forward hops on bosu ball & 30 sec. & 30 sec. \\
\hline Double-leg side hops on bosu ball & 30 sec. & 30 sec. \\
\hline Double-leg trampoline jumping and landing $180^{\circ}$ & 30 sec. & 30 sec. \\
\hline Tuck jumps on bosu ball & & 30 sec. \\
\hline Single-leg forward hops on bosu ball & & 30 sec. \\
\hline Single-leg side hops on bosu ball & & 30 sec. \\
\hline
\end{tabular}

\section{References}

Alpay, C. B., \& Işık, Ö. (2017). Comparison of body components and balance levels among hearing-impaired wrestlers and healthy wrestlers. Acta Kinesiologica, 11(1), 79-84.

Atan, S.A. (2009). The Effects of a Four-Week Balance Training Programme on Dynamic Balance and Soccer Skill Performances, Master of Sports Science Faculty of Sports Science and Recreation.

Atılgan, O. (2013). Effects of trampoline training on jump, leg strength, static and dynamic balance of boys. Science of Gymnastics Journal, 5(2), 15-25.

Bangsbo L. (1996) Futbolda Fizik Kondisyon Antrenmanı, TTF Eğitim Yayınları (Ylua Hells’ten çeviri), Ares Matbaacılık, İstanbul.

Blackburn, T., Cuskiewicz, K. M., Petschauer, M. A., \& Prentice, W. E. (2000). Balance and Joint Stability: The Relative Contributions of Proprioception and Muscular Strength, Journal of Sport Rehabilitation, 9, 315-328. https://doi.org/10.1123/jsr.9.4.315

Bloomfield, J., Polman, R., O’Donoghue, P., \& McNaughton, L. (2007). Effective Speed and Agility Conditioning Methodology for Random Intermittent Dynamic Type Sports, Journal of Strength and Conditioning Research, 21(4), 1093-1100. https://doi.org/10.1519/00124278-200711000-00020

Çelenk, Ç., Arslan, H., Aktuğ, Z. B., \& Şimşek, E. (2018). The Comparison Between Static and Dynamic Balance Performances of Team and Individual Athletes, European Journal of Physical Education and Sport Science, 4(1).

Chaouachi, A., Othman, B. A., Hammami, R., Drinkwater, E. J., \& Behm, D. G. (2014). The Combination of Plyometric and Balance Training Improves Sprint and Shuttle Run Performances More Often Than Plyometric-Only Training with Children, Journal of Strenght and Conditioning Association, 28(2), 401-412. https://doi.org/10.1519/JSC.0b013e3182987059

Dunsky, A., Barzilay, I., \& Fox, O. (2017). Effect of a specialized injury prevention program on static balance, dynamic balance and kicking accuracy of young soccer players. World $J$ Orthop, 8(4), 317-321. https://doi.org/10.5312/wjo.v8.i4.317

Erdem, K., \& Akyüz, C. (2017). The Effect of Core and Balance Training on Single-Leg Sway Parameters and Well-Directed Kick of Male Soccer Players. European Journal of Physical Education and Sport Science, 3(12).

Evangelos, B., Georgios, K., Konstantinos, A., Gissis, I., Papadopoulos, C., \& Aristomenis, S. (2012). Proprioception and balance training can improve amateur soccer players' technical skills. Journal of Physical Education and Sport, 12(1), 81-89.

Filipa, A., Byrnes, R., \& Hewett, T. E. (2010). Neuromuscular Training Improves Performance on The Star Excursion Balance Test in Young Female Athletes, J Orthop Sports Phys Theraphy, 40(9), 551-558. https://doi.org/10.2519/jospt.2010.3325

Helgerud, J., Engen, L. C., Wisloff, U., \& Hoff, J. (2001). Aerobic Endurance Training Improves Soccer Performance, Medicine and Science in Sports and Exercise, 33, 1925-1931. https://doi.org/10.1097/00005768-200111000-00019

Jakobsen, M. D., Sundsrup, E., Krustrup, P., \& Aagaard, P. (2010). The effect of recreational soccer training and running on postural balance in untrained men. European Journal of Applied Physiology, 111 (3), 521-530. https://doi.org/10.1007/s00421-010-1669-2 
Little, T., \& Williams, A. G. (2005). Specificity of Acceleration, Maximum Speed, and Agility in Professional Soccer Players, National Strength \& Conditioning Association, 19(1), 76-78. https://doi.org/10.1519/00124278-200502000-00013

Malina, R. M., Eisenmann, J. C., Cumming, S. P., Ribeiro, B., \& Aroso, J. (2004). Maturity-Associated Variation in the Growth and Functional Capacities of Youth Football (Soccer) Players 13-15 Years, European Journal of Applied Physiology, 91(5-6), 555-562. https://doi.org/10.1007/s00421-003-0995-z

McLeod, T. C., Armstrong, T., Miller, M., \& Sauers, J. L. (2009). Balance Improvements in Female High School Basketball Players After a 6 Week Neuromuscular Training Program, Journal of Sport Rehabilitation, 18(4), 465481. https://doi.org/10.1123/jsr.18.4.465

Melo, R. S., Marinho, S. E. S., Freire, M. E. A., Souza, R. A., Damasceno, H. A. M., \& Raposo, M. C. F. (2017). Static and dynamic balance of children and adolescents with sensorineural hearing loss. Einstein (São Paulo), 15(3). https://doi.org/10.1590/s1679-45082017ao3976

Myer, G. D., Ford, K. R., \& Hewett, T. E. (2004). Methodological Approaches and Rationale for Training to Prevent Anterior Cruciate Ligament Injuries in Female Athletes, Scandinavian Journal of Medicine \& Science in Sports, 14(5), 275-285. https://doi.org/10.1111/j.1600-0838.2004.00410.x

Özmen, Ö. (1999). Futbolcu Kondisyonu ve Sportif Form, Futbol Eğitim, 16, 4-5.

Paillard, T., Noe, F., Riviere, T., Marion, V., Montaya, R., \& Dupui, P. (2006). Postural Performance and Strategy in the Unipedal Stance of Soccer Players at Different Levels of Competition', Journal of Athletic Training, 41(2), 172-176.

Plisky, P. J., Rauh, M. J., Kaminski, T. W., \& Underwood, F. B. (2006). Star Excursion Balance Test as a predictor of lower extremity injury in high school basketball players. J Orthop Sports Phys Ther, 36(12), 911-919. https://doi.org/10.2519/jospt.2006.2244

Reilly, T., Bangsbo, L., \& Franks, A. (2000). Anthropometric and Physiological Predispositions for Elite Soccer', J. of Sports Sciences, 18, 669-683. https://doi.org/10.1080/02640410050120050

Ringhof, S., \& Stein, T. (2018). Biomechanical assessment of dynamic balance: Specificity of different balance tests, Human Movement Science, 58, 140-147. https://doi.org/10.1016/j.humov.2018.02.004

Shaffer, S. W., Teyhen, D. S., Lorenson, C. L., Warren, R. L., Koreerat, C. M., Straseske, C. A., \& Childs, J. D. (2013). Y-Balance Test: a reliability study involving multiple raters. Mil Med. 178(11), 1264-1270. https://doi.org/10.7205/MILMED-D-13-00222

Sharma, S., \& Multani, N. K. (2017). Relationship of Dynamic Balance with Lower Extremity Muscular Strength and Endurance in Football Players, Indian Journal of Research, 6(11).

Tropp, H., Ekstrand, J., \& Gillquist, J. (1984). Factors Affecting Stabiliometry Recordings of Single Limb Stance, Am. J. Sports Med., 12(3), 185-188. https://doi.org/10.1177/036354658401200302

Yaggie, J. A., \& Campbell, B. M. (2006). Effects of Balance Training on Selected Skills, Journal of Strenght and Conditioning, 20(2), 422-428. https://doi.org/10.1519/00124278-200605000-00031

Zech, A., Hubscher, M., Vogt, L., Banzer, W., Hansel, F., \& Pfeifer, K. (2010). Balance Training for Neuromuscular Control and Performance Enhancement: A Systematic Review, National Athletic Trainers Association, 45(4). https://doi.org/10.4085/1062-6050-45.4.392

\section{Copyrights}

Copyright for this article is retained by the author(s), with first publication rights granted to the journal.

This is an open-access article distributed under the terms and conditions of the Creative Commons Attribution license which permits unrestricted use, distribution, and reproduction in any medium, provided the original work is properly cited. 